\title{
Polymorphic variation and phylogeny of the myostatin gene in wild Punjab Urial (Ovis vignei punjabiensis)
}

\author{
Asad Ullah Ghalib ${ }^{1}$, Tanveer Hussain ${ }^{1 *}$, Abdul Wajid ${ }^{1}$, Ahmad Ali ${ }^{2}$,
} Akhtar Ali ${ }^{1}$, Zulfiqar Hussain Kuthu ${ }^{3}$, Shahzad $\mathrm{Akbar}^{3}$ and Kamran Abbas $^{1}$

1. Department of Molecular Biology, Virtual University of Pakistan, Lahore-Pakistan

2. COMSATS University Islamabad, Sahiwal campus-Pakistan

3. University of Poonch, Rawalakot, Azad Jammu \& Kashmir-Pakistan

*Corresponding author's email: tanveer.hussain@vu.edu.pk

Citation

Asad Ullah Ghalib, Tanveer Hussain, Abdul Wajid, Ahmad Ali, Akhtar Ali, Zulfiqar Hussain Kuthu, Shahzad Akbar and Kamran Abbas. Polymorphic variation and phylogeny of the myostatin gene in wild Punjab Urial (Ovis vignei punjabiensis). Pure and Applied Biology. Vol. 8, Issue 3, pp1596-1602.

http://dx.doi.org/10.19045/bspab.2020.90167

Received: 14/04/2019 Revised: 24/07/2019

Accepted: 27/07/2019

Online First: 19/03/2020

\section{Abstract}

Myostatin (MSTN) also known as GDF-8 (growth and differentiation factor-8) is a member of transforming growth factor $\beta$ superfamily. It acts as a negative-regulator for growth of skeletal muscle and differentiation in mammals. The genetic variation in MSTN gene has been linked to the variation in the muscularity in animals. However, study on variation in MSTN gene in wild animals is limited. In this research work, the 5' UTR (untranslated region) and exon-1 of MSTN gene was studied in Wild Punjab Urial (Ovis vignei punjabiensis) that is endemic to Northern Punjab. The direct sequence analysis showed one substitution (g.3564 C>A) and one indel (g.3574 deletion) in the 5-UTR region of MSTN gene in Punjab Urial. The phylogenetic analysis was performed among various species and the clustering result of these species was consistent with fact of species differentiation. In this study, we hypothesized that the variation within the selected gene may be important in identifying the genomic region that would be responsible for significant phenotypes in the studied animal. The identifying variation could be used in the selection of Urial for environmental adaptation and domestication.

Keywords: Myostatin gene; sequencing; polymorphisms; Punjab Urial; Pakistan

Introduction

Myostatin, also known as GDF-8 (growth differentiation factor-8), is a member of TGF- $\beta$ superfamily (a mammalian growth transforming family) and is encoded by myostatin $(M S T N)$ gene. This is a negative regulator of growth and skeletal muscle development in the mammals [1]. Myostatin or GDF-8 expressed specifically in developing an adult skeletal muscle particularly in the muscles of posterior part of animal the femur muscles as shown in many breeds of cattle and sheep. Molecular analysis of MSTN gene in Nile Tilapia (Orechromis niloticus) showed that it consists of two introns (1840 and 233 
nucleotides in each intron) and three exons (373, 374 and 381 nucleotides in each exon) [2]. Because of the potential applications in animal husbandry and a key role in the muscle growth, myostatin (MSTN) is considered as an important candidate gene for the development and growth of domestic animals [3].

Previously, it has been described the meat productivity is affected by nucleotide substitutions in MSTN gene. Mutation of c. $101 \mathrm{~A}>\mathrm{G}$ in the exon-1 alters the structure of the myostatin propeptide [4]. In the 34 codon glutamic acid is substituted by glycine. Since these two amino acids have big differences in the structure, it can be assumed that this change affects the ability of myostatin inhibition, and further on meat quality. This SNP found in Merino sheep, NC Romney, Corriedale and New Zealand hybrids $[5,6]$. Zhou et al. studied variation into coding region of the MSTN gene in the sheep. In the study, they reported the detection of three alleles as well as they also identified variation in the sequence of ovine GDF8 coding region through PCR-SSCP and sequence analysis. In past several studies have been done that focused on correlation between polymorphism of theMSTN gene and the growth traits in chicken, cattle and pig [7]. The variation in the MSTN gene has been linked with the muscling in several mammalian species including cattle, dogs, mice, pigs, sheep and human, [8]. Therefore, the objective of this study was to determine the genetic polymorphism of myostatin gene and its relationship with the growth performance of the Wild Punjab Urial (Ovis vignei punjabiensis) [2].

The Urial (Ovis vignei) which is also known as an ancestor of Ovis aries (domestic sheep) is a wild sheep of medium size. Taxonomic status of species and subspecies of Urial is unclear yet. Three subspecies of Urial present in Pakistan are named as the Afghan Urial $(O$. orientalis (vignei) cycloceros including $O . v$. blandordi: the former considered to be occurring north of Quetta and the latter south of Quetta and in Sindh west of Indus), Punjab Urial (O. orientalis (vignei) punjabiensis), and Ladakh Urial (O. orientalis vignei or $O$. vignei vignei) [9]. The differentiation in these three sub species is on the basis of color of ruff. Due to many threats, all these subspecies of the Urial have been considered globally as the vulnerable and these are added into the 'IUCN Red list of the Threatened Animals (2015) [10]. Due to habitat deterioration, hunting and hybridization their population is believe to be going towards decline (of $\sim 30 \%$ ) over three generations.

Punjab Urial (Ovis vignei punjabiensis) is an endemic as well as endangered breed of the sheep that belongs to the Pakistan. Pakistan is facing several serious threats of the extinction of this breed because of poaching, exploitation of natural resources, infrastructure construction projects, habitats loss, pet trade, fast urbanization, grazing, road vehicles and many agricultural practices [10]. Though the Punjab Urial is known as an animal of the special interest among the wild mammals of Pakistan, still there is scarcity and limitation of the studies on the genomic diversity as well as reports for exploration of molecular genetic diversity and the phylogeny for their comparison to other mammals [11]. The MSTN is an important gene to be used for the detection of polymorphism as well as the association studies related to the selective breeding for different traits such as carcass and muscle growth in livestock [2].

As the MSTN gene have various significant pleiotropic effects such as its role in the muscle mass development, the polymorphism in the gene could contribute in explaining the morphological variability among the different breeds [12]. Here the intron 1 and exon 1 of MSTN gene in Punjab Urial was amplified and sequenced to study the polymorphic variations and phylogeny to 
evaluate their potential association with the different morphological types [12].

\section{Materials and methods}

\section{Ethical statement}

This research work on animals was approved by the Departmental Ethical Research Committee of the Virtual University of Pakistan.

\section{Sample selection}

Punjab Urial is distributed in Northern Punjab at elevators of 250-1500 meters between the Indus and Jhelum rivers in the Kala Chitta and Salt Ranges. The skin samples were provided by the Punjab Wildlife Department and blood samples were collected from Zoo and captured animals after necessary permissions. Skins samples collected from Punjab Urial were concealed in sterilized zipper bags and brought into molecular biology laboratory of Virtual University of Pakistan, 1-Davis Road, Lahore.

\section{DNA extraction from skin samples}

In this procedure, $2 \mathrm{mg}$ skin tissue was clean with surgical blade and $70 \%$ ethanol and chopped into small pieces. The tissues were homogenized in lysis buffer (Tris $\mathrm{HCl}$ $10 \mathrm{Mm}$, EDTA-2Mm), and the homogenate was transferred into eppendorf tube. The homogenate was mix with sodium dodecyl sulphate-SDS $(10 \%)$, proteinase $\mathrm{k}(20 \mathrm{mg} / \mathrm{ml})$ and TNE buffer (Tris HCl-10Mm, NaCl-2 M, EDTA-2Mm), vortex slightly and place in shaking water bath on $58{ }^{\circ} \mathrm{C}$ overnight. The remaining steps were performed through Phenol-Chloroform Isoamyl Alcohol (PCI) method previously described by Wajid et al. [13].

\section{PCR amplification}

In this study primer pair (forward primer 5'CAAGTTGTCTCTCAGACTGG $-3^{\prime}$, and reverse primer 5'ACACTAGAACAGCAGTCAGC-3') was used to amplify the fragment size of 544 base pair [bp] containing the 5' untranslated region (UTR), and complete coding region of exon 1 of the MSTN gene. The PCR reaction was prepared in $25 \mu$ l containing genomic 2 $\mu 1$ DNA (10 ng/ $\mu \mathrm{l}), 1 \mu \mathrm{l}$ each forward and reverser primers (10 pM), $2 \mu \mathrm{l}$ dNTPs $(50 \mu \mathrm{M}), 2 \mu \mathrm{l} \mathrm{MgCl}_{2}(3 \mathrm{mM}), 6 \mu 110 \mathrm{mM}$ Taq Buffer (NH4) ${ }_{2} \mathrm{SO}_{4}, 5 \mathrm{U}$ Taq polymerase (Fermentas, USA) $0.5 \mu \mathrm{l}$ and $13.5 \mu \mathrm{l}$ UltraPure DEPC-Treated water. PCR condition was standardized of initial denaturation at $95^{\circ} \mathrm{C}$ for 7 minutes, Denaturation at $95^{\circ} \mathrm{C}$ for 1 minute, annealing at $59^{\circ} \mathrm{C}$ for 1 minutes, extension at $72^{\circ} \mathrm{C}$ for 1 minute seconds and final extension was optimized at $72^{\circ} \mathrm{C}$ for 10 minutes. The PCR products were cleaned through $70 \%$ ethanol and sequenced through ABI automated sequencer (Applied Biosystems, Inc., Foster City, CA).

\section{Data analysis}

The MSTN gene sequences were edited, assembled and analyzed for single nucleotide polymorphisms (SNPs) through BLAST and by BioEdit v7 [14]. The aligned sequences were analyzed further for phylogenetic analysis in comparison with GenBank NCBI reported sequences using MEGA 6.0software. The "build" function of ETE3 v3.0.0b32 [15] as executed on the GenomeNet

(http://www.genome.jp/tools/ete/) was used to perform the phylogenetic reconstructions.

\section{Results}

In the current study, the myostatin (MSTN) gene previously referred as GDF8 gene was studied in Punjab Urial sheep, a wild sheep breed rearing in the North region of Punjab province. Our sequences contained partial 5 , - untranslated region (UTR), 67 base pair upstream from ATG (start codon) and complete exon 1 (372 bp) of the MSTN gene. The partial sequence of 5'-UTR exhibited one substitution (g.3564 C>A) and one indel (deletion g.3574) (Fig. 1). The complete sequences of exon-1 of MSTN gene in Punjab Urial were compared with the sequences available in GenBank for detection of 
polymorphism. The analysis identified that all the investigated Punjab Urial sequences were found conserved and not polymorphism was detected in exon-1 region of MSTN gene. One polymorphism (g. 3975 deletion) was identified in intron 1 region of the MSTN gene in the investigated sequences.

For inference of the evolutionary history Neighbor-Joining method was used and the evolutionary distances were calculated using Maximum Composite Likelihood method. The phylogenetic tree included eighteen $M S T N$-gene sequences from the investigated wild Urial sheep and compared with domesticated sheep and other animals including goat, cattle, yak, buffalo, horse and pig sequences. The phylogenetic analysis revealed that the domestic and wild sheep were the closely related to each other. Ovine family was more closely related to Capra hircus as they share the common ancestor (Fig. 2).

\section{Discussion}

The present study describes the polymorphic variation and phylogeny of the MSTN (myostatin) gene's 5-UTR region and Exon 1 in wild Punjab Urial (Ovis vignei punjabiensis). Myostatin is known as an important member of TGF (the transforming growth factor) family, and play significant role in regulating the growth of the skeletal muscle growth in all animals. It is also known as GDF-8 (Growth and Differentiation factor-8) and reported in several animals due to its economic significance. It contains two introns and three exons that regulate its function. The genetic variation in MSTN gene have been studied in Belgian blue sheep, Texal sheep, Makuei sheep, various breeds of goat, cattle, dog, pig, horse, mouse, chicken and human. Mutation in myostatin leads to dysfunctions or inhibition of this gene resulting double muscling [16].

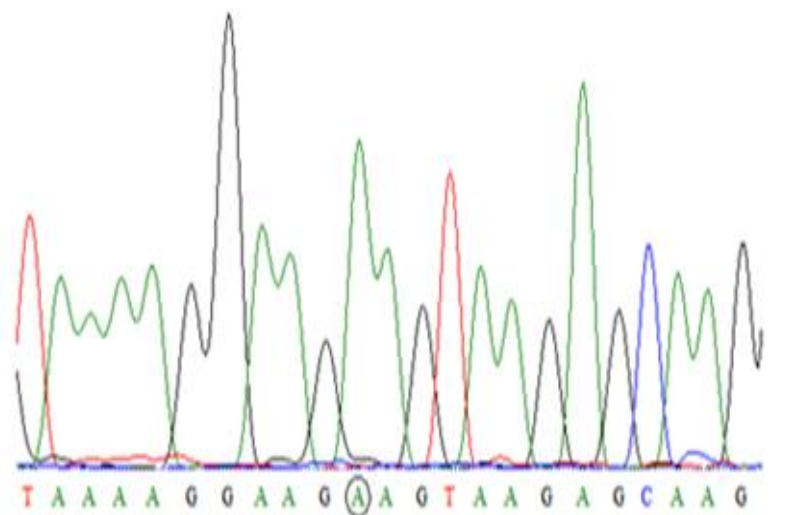

$3564 \mathrm{C}>\mathrm{A}$

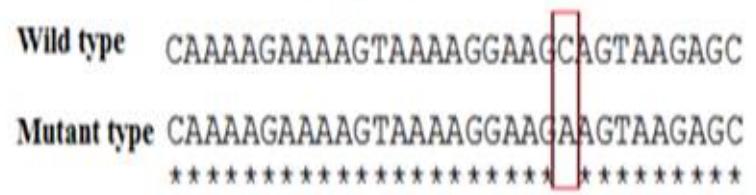

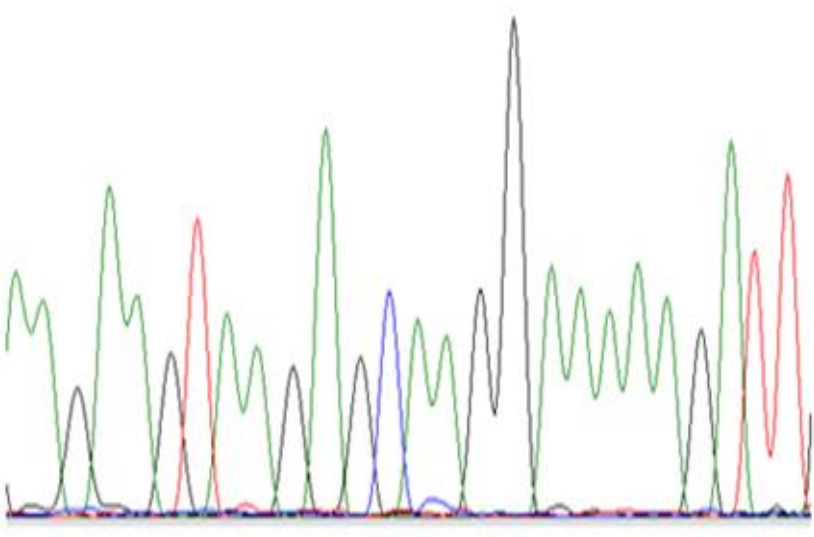

3574 Indel (Deletion)

Wild tipe AAGCAGTAAGAGDTAAGGAAAAGATT

Mutant țpe AAGAAGTAAGAGC-AAGGAAAAGATT

$\star * * * * * * * * * * *+* * * * * * * * * * * *$

Figure 1. (A) The substitution of Adenine with Cytosine (g. $3564 \mathrm{~A}>\mathrm{C}$ ) (B) Indel (deletion g.3574) (compared with GenBank accession number: AF019622) 


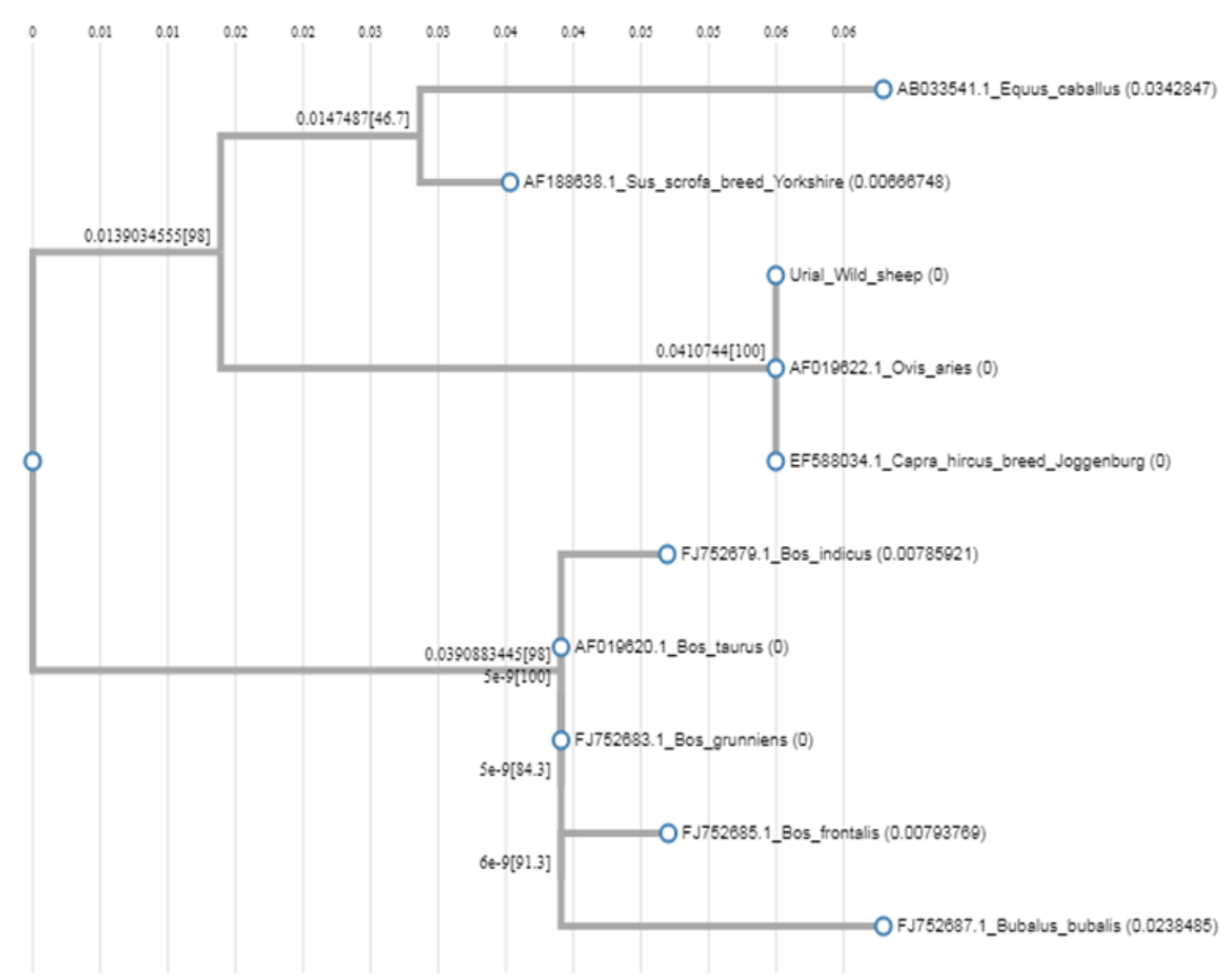

Figure 2. Phylogenetic tree constructed using the function "build" of ETE3 v3.0.0b32 [12] as implemented on the Genome Net (http://www.genome.jp/tools/ete/)

In the current study fragment size of $544 \mathrm{bp}$ containing the 5' untranslated region (UTR), and complete coding region of the exon 1 of the MSTN gene was amplified, sequenced and analyzed. Results of sequencing showed that exon 1 of MSTN gene was conserved as no mutation was observed in this region. The partial sequence of 5'-UTR exhibited one substitution (g.3564 A>C) and one indel (deletion g.3574). The untranslated regions have great role in gene enhancer or suppressor, as the 5' - UTR contain the promoter sequences that is binding motif for transcriptional machinery so if this regions are affected so the transcriptional activity of the corresponding gene would be affected [17].
Among carriers of New Zealand Romney mutations are $2 \%$ of the animals [6]. Substitution of c.*1232 G>A into 3'UTR of the MSTN gene of sheep can be used as a marker for genomic selection. The animals carrying two copies of the allele $\mathrm{A}$, have a broad chest and back, and a well-developed musculature. The estimated weight of loin primal cuts, chum and hind leg were observed increased significantly [18]. Other previous studies reported three mutations on position number 224bp, 226bp and 242bp in $M S T N$ exon 1 of makuei sheep that were found responsible for increase heart girth and leg circumference [19] Similarly two mutations were found in Iranian Markhoz goats' exon 1 of MSTN gene that was 
responsible for double muscling [20]. Not only in sheep goat and cattle MSTN has also been reported for double muscling in fish exon 2 [20]. In Russian sheep six potential mutations were reported out of which 3 were causing double muscling [4].

By various studies in the past phylogeny of Myostatin (MSTN) gene has been assessed widely and those studies are largely consistent with this current study. To infer evolutionary history phylogenetic tree was built through the Neighbor-Joining method whereas the evolutionary distances were calculated using Maximum Composite Likelihood method. The phylogenetic tree included eighteen $M S T N$-gene sequences from the investigated wild Urial sheep and compared with domesticated sheep and other animals including goat, cattle, yak, buffalo, horse and pig sequences. The phylogenetic analysis of myostatin (MSTN) gene with different other related genes has confirmed the evolutionary relationships of our isolated sequence. The phylogenetic analysis revealed that the domestic and wild sheep were the closely related to each other. Ovine family was more closely related to Capra hircus as they share the common ancestor [4]. This study showed highly conserved MSTN gene exon and variable non-coding region in wild animal.

\section{Conclusion}

This study on genetic variations in MSTN gene in wild Punjab Urial is first of its kind from Pakistan. The identified variations may be further studied all type of Urial in Pakistan as well as in other wild mammals to have more insight of this genomic region and its possible use for animal welfare in future.

\section{Authors' contributions}

Conceived and designed the experiments: $\mathrm{T}$ Hussain \& A Wajid. Performed the experiments: AU Ghalib, \& K Abbas. Analyzed the data: A Wajid, AU Ghalib, A Ali, A Ali, \& ZH Kuthu. Contributed materials/ analysis/ tools: AU Ghalib, T
Hussain, A Wajid \& S Akbar. Wrote the paper: A Wajid \& AU Ghalib.

\section{Acknowledgements}

Pakistan Wildlife Foundation, Islamabad and Lahore Zoo is acknowledged for their kind help in sample collection.

\section{References}

1. Obstye TK, Wetten OF, Klunderud AT, Jakobsen KS, Yafe A, Etzioni S, Moen T \& Andersen O (2007). Myostatin (MSTN) gene duplications in Atlantic salmon (Salmo salar): Evidence for different selective pressure on teleost MSTN-1 and -2. Gene 403: 159-169.

2. Ismail MI, Mourad MM, Rashed MA \& Ramadan IS (2017). Myostatin gene sequencing and its Association with growth performance of maghrabi camel breed. Egyp J Desert Res 67(1): 115-124.

3. Bellinge RHS, Liberles DA, Laschi SPA, Brien PAO \& Tay GK (2005). Myostatin and its implications on animal breeding: a review. Animal genetics 36(1): 1-6.

4. Dunner S, Miranda ME, Amigues Y, Canron J, Georges M, Hanset R, Williams JL, Ménissier F (2003). Haplotype diversity of the myostatin gene among beef cattle breeds. Genet Sel Evol 35: 103118.

5. Han J, Zhou H, Forrest RH, Sedcole JR, Frampton CM, Hickford JGH (2010). Effect of Myostatin (MSTN)g+6223G>A on production and carcass traits in New Zealand Romney sheep. Asian-Aust. $J$ Animal Sci 23: 863-866.

6. Han, J., R. Forrest, \& J. Hickford (2013). Genetic variations in the myostatin gene (MSTN) in New Zealand sheep breeds. Mol Biol Rep 40(11): 6379-6384.

7. Gong, YF, Li XL, Liu ZZ, Jin XM, Zhou RY, Li LH \& Zhang Q (2009). SNP Detection and Haplotype Analysis in Partial Sequence of MSTN Gene in Sheep. Russian J Genet 45(12): 1454-1457.

8. Muzzachi S, Oulmouden A, Cherifi Y, Yahyaoui H, Zayed MA, Burger P, Lacalandra GM, Faye B \& Ciani1 E (2015). Sequence and polymorphism 
analysis of the camel (Camelus dromedarius) myostatin gene. Emir $J$ Food Agric 27(4): 367-373.

9. Shackleton DM (1997). Wild sheep and goats and their relatives: Status survey and conservation action plan. IUCN/SSC Caprinae Specialist Group. IUCN, Switzerland and Cambridge, UK.

10. Siraj-ud-Din M, Minhas RA, Khan M, Ali U, Shaista S, Ahmed B \& Awan MS (2016). Conservation Status of Ladakh Urial (Ovis vignei vignei Blyth, 1841) in Gilgit Baltistan, Pakistan. Pak J Zool 48(5): 1353-1365

11. Hussain T, Babar ME, Musthafa MM, Saif R, Hussain F, Aqeel M, Naveed N, Pervez MT, Khan AW, Ziaullah, Shahzad S \& Yaqub A (2015). Mitochondrial ATP6 and ATP8 genes based Molecular Diversity and Phylogenetic analysis in Punjab Urial (Ovis vignei punjabiensis). The J Anim \& Plant Sci 25(3): 311-318.

12. Olio SD, Fontanesi L, Costa LN, Tassinari M, Minieri L \& Falaschini A (2010). Analysis of Horse Myostatin Gene and Identification of Single Nucleotide Polymorphisms in Breeds of Different Morphological Types. J Biomed \& Biotech 2010: 1-11.

13. Wajid A, Wasim M, Yaqub T, Firyal S, Tayyab M, Siddique $S$ \& Hussain $T$ (2014). Assessment of genetic diversity in balochi and rakhshani sheep Breeds of balochistan using microsatellite dna markers. J Anim \& Plant Sci 24(5): 13481354

14. Hall TA (1999). BioEdit: a user-friendly biological sequence alignment editor and analysis program for Windows 95/98/NT. Nucl Acid S. 41: 95.

15. Huerta-Cepas J, Serra F \& Bork P (2016). ETE 3: Reconstruction, Analysis, and
Visualization of Phylogenomic Data. Mol Biol \& Evol 33(6): 1635-1638.

16. Proudfoot, C, Carlson DF, Huddart R, Long CR, Pryor JH, King TJ, Lillico SG, Miliham AJ, McLaren DG, Whitelaw CBA \& Fahrenkrung SC (2015). Genome edited sheep and cattle. Transgenic Res 24(1): 147-153.

17. Niu, D, Wang L, Bai Z, Xie S, Zhao H \& Li J (2015). Identification and expression characterization of the myostatin (MSTN) gene and association analysis with growth traits in the razor clam Sinonovacula constricta. Gene 555(2): 297-304.

18. Masria AY, Lambea NR, Macfarlanea JM, Brotherstoneb S, Haresignc W, Büngera L (2011). Evaluating the effects of the c. ${ }^{*} 1232 \mathrm{G}>\mathrm{A}$ mutation and TM-QTL in Texel $\times$ Welsh Mountain lambs using ultrasound and video image analyses. Small Ruminant Res 99: 99-109.

19. Khani K, Abdolmohammadi A, Foroutanifar S, Zebarjadi A (2017). Assessment of polymorphisms in mysostatin gene and their allele substitution effects showed weak association with growth traits in Iranian Markhoz goats. The J of Agric Sci 155(3): 519-526.

20. Elkatatny NA, Elbialy ZI, El-Nahas AF, Mahmoud S (2016). Characterization of Myostatin Gene in Nile Tilapia (Oreochromis niloticus), the Possible Association of BsmI-exon 2 Polymorphism with Its Growth. Am J Life Sci 4(3): 82-86.

21. Bhattacharya T, Shukla R, Chatterjee R, Dushyanth K (2017). Knock down of the myostatin gene by RNA interference increased body weight in chicken. $J$ of Biotechnol 241: 61-68. 